Ophthalmic Hospital, and as President of the Ophthalmological Society of the United Kingdom, he has been and is intimately concerned with the teaching of ophthalmology to undergraduate and post-graduate students, and with the qualifications which are indubitably requisite in applicants for the position of ophthalmic surgeon to hospitals and infirmaries and for ophthalmic posts under the Ministry of Health, the Board of Education, and the County Councils. The votes of Fellows of the College who are ophthalmic surgeons will not alone suffice to secure Mr. Fisher's election, and it is to be hoped that other voters will recognize the importance of securing the due representation of ophthalmology on the Council.

\title{
The Guild of Blind Gardeners
}

The letter which we publish in this issue under the signature of Mrs. Adolphus Duncombe, is one which is sure to command the sympathetic attention of ophthalmic surgeons. Mrs. Duncombe is a lady well known in London society, and is another illustration of the magnificent courage with which men and women, who having lost their sight after many years of the fullest enjoyment of it, have refused to bow to misfortune and determine instead to spend themselves in the service of those to whom life has offered fewer alleviations when overtaken by the disaster of blindness. A keen gardener in former days, she has drafted a scheme for a School of Gardening and Farming for the Blind, and has enlisted the services of a number of well known people, including several ophthalmic surgeons. "The object of the Guild is to encourage the blind to undertake gardening as a healthy and interesting occupation in addition to any sedentary work they may be engaged in," as well as to fit those, who desire to do so, to earn a living thereby. Mrs. Duncombe and her colleagues are most anxious to get into full touch with ophthalmic surgeons and other medical men, whose work brings them into contact with the class of people in whose interests this work is undertaken.

\section{ABSTRACTS}

\section{I.- $\overline{\text { MYOPIA }}$}

Edridge-Green, F. W.-On the cause and prevention of myopia. Lancet, March 5, $192 \mathrm{I}$.

In his Arris and Gale Lecture, Edridge-Green re-states, and in some respects amplifies, the argument originally published in the 